\title{
A case report of fatal disseminated fungal sepsis in a patient with ARDS and extracorporeal membrane oxygenation
}

\author{
Stefanie Prohaska ${ }^{*^{*}}$ D, Philipp Henn', Svetlana Wenz ${ }^{2}$, Leonie Frauenfeld ${ }^{2}$, Peter Rosenberger ${ }^{1}$ and
} Helene A. Haeberle ${ }^{1}$

\begin{abstract}
Background: With the following report we want to present an unusual case of a patient suffering from acute respiratory distress syndrome with early discovery of bacterial pathogens in bronchoalveolar liquid samples that developed a fatal undiscovered disseminated fungal infection.

Case presentation: A 67-year-old man was admitted to our university hospital with dyspnea. Progressive respiratory failure developed leading to admission to the intensive care unit, intubation and prone positioning was necessary. To ensure adequate oxygenation and lung protective ventilation veno-venous extracorporeal membrane oxygenation was established. Despite maximal therapy and adequate antiinfective therapy of all discovered pathogens the condition of the patient declined further and he deceased. Postmortem autopsy revealed Mucor and Aspergillus mycelium in multiple organs such as lung, heart and pancreas as the underlying cause of his deterioration and death.

Conclusion: Routine screening re-evaluation of every infection is essential for adequate initiation and discontinuation of every antiinfective therapy. In cases with unexplained deterioration and unsuccessful sampling the possibility for diagnostic biopsies should be considered.
\end{abstract}

Keywords: Mucormycosis, ARDS, ECMO

\section{Introduction}

ARDS may be caused by a variety of conditions but in immunocompromised patients it is mainly due to infection. In this patient the pattern of infection by Pneumocystis jiroveci, Staphylococcus aureus/MSSA, Candida dubliniensis, Cytomegalovirus and Legionella pneumophila reflecst the compromised immune function. The mortality of immunosuppressed patients suffering ARDS is increased [1] regardless of the severity of the disease. Polimicrobial infections are seen regularly in

\footnotetext{
*Correspondence: Stefanie.prohaska@med.uni-tuebingen.de

'Department of Anesthesiology and Intensive Care Medicine, Intensivstation 39, Tübingen University Hospital, Eberhard-Karls-University, Hoppe-Seyler-Str. 3, 72076 Tübingen, Germany

Full list of author information is available at the end of the article
}

immunocompromised critically ill patients. Fungal coinfections were described in children [2] and adults suffering ARDS [3, 4] due to viral infections. Pneumocystis jiroveci is often found in immunocompromised patients [5], as is the reactivation of Cytomegalovirus [6].

The differentiation of fungal contamination or infection in non-hematological patients may be challenging. Risk factors for fungal infections or coinfections in nonhematological ICU-patients are numerous, but not suitable as a distinguishing factor between infection and contamination. Diagnostics and first line treatment of the most common invasive fungal infections are listed in Table 1. 
Table 1 most common invasive fungal infections [7] with additional diagnostics and first line treatment [8-11]

\begin{tabular}{llll}
\hline & Diagnostics & & Treatment \\
\hline Candida spp. & Direct microscopy and histopathology, cultur & Blood cultures & Echinocandins \\
& & B-D-Glucan & Serum-Mannan/ anti-Mannan (in Candidaemia) \\
Aspergillus spp. & $\mathrm{CT}$ (chest) & Isacuconazol \\
& Galactomannan (Serum, BAL) & Voriconazol \\
Mucorales & $\mathrm{CT}$ (chest) & Surgical debridement \\
& & Lipos. Amphotericin B \\
& & Posaconazol (salvage treatment)
\end{tabular}

The reported single cases about mucormycosis increased lately. Most cases were described in patients with malignancies, organ transplantation, HIV or DM (recently reviewed in [12]). Recently Jiang and coworkers suggested the liquid-based cytopathology to identify mucorales promptly in samples obtained by bronchial brushes [13]. Much like with conventional cultures, the result may be difficult to interpret due to overgrowth.

\section{Case presentation}

A 67-year-old man with progressive dyspnea over 2 days was presented to the emergency department. Due to respiratory insufficiency he required intubation and initiation of mechanical ventilation and was therefore directly admitted to the ICU. The patient had a history of high-dose steroid therapy (dexamethasone $24 \mathrm{mg}$ /day) for 5 weeks prior because of a spinal (suspected ependymoma presenting with spinal bleeding and paraplegia). His body temperature peaked at $40.4^{\circ} \mathrm{C}$ approximately 2 $\mathrm{h}$ after admittance to the ICU. Leukocyte counts were normal but $\mathrm{C}$-reactive protein (CRP) and Procalcitonin
(PCT) levels were elevated (CRP $45.05 \mathrm{mg} / \mathrm{ml}$, PCT 5.59 $\mathrm{ng} / \mathrm{ml})$. Several blood and BAL samples were taken for microbiological diagnosis. Anti-infective therapy was started with Piperacillin/Tazobactam and Clarithromycin in accordance with the local standard. On the following day CT scan showed bipulmonary infiltrates and no signs of pulmonary embolism (Fig. 1). At this point adequate ventilation required high driving pressures $\left(\mathrm{paO}_{2} / \mathrm{FiO}_{2} 77\right.$, pressure control ventilation, $\mathrm{Pmax} 32$ mbar). Tidal volume goals were calculated with $6 \mathrm{ml} / \mathrm{kg}$ body weight. Prone positioning for about $19 \mathrm{~h}$ significantly improved the patient's oxygenation and ventilation settings $\left(\mathrm{paO}_{2} / \mathrm{FiO}_{2}\right.$ 207, pressure control ventilation, Pmax 24 mbar). On the second day we received the first results from the bronchoalveolar lavage. PCR for Pneumocystis jiroveci, Legionella species and Cytomegalovirus was positive. PCT levels peaked at $63.02 \mathrm{ng} / \mathrm{ml}$ and CRP levels at $56.18 \mathrm{mg} / \mathrm{ml}$ while leukocyte counts were remaining within normal range. Anti-infective therapy was changed to Primaquine, Clindamycin, Ganciclovir and Levofloxacin. Results from

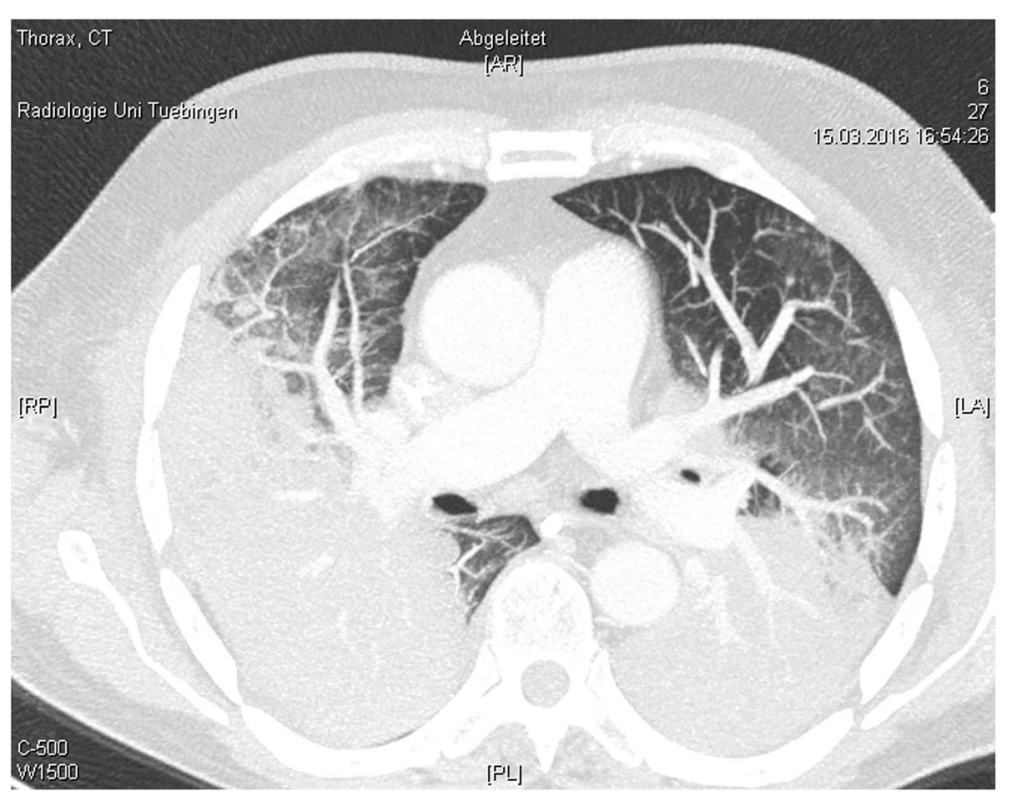

Fig. 1 CT scan of the lung on day 1 after admission 
PCR and cultures 2 days later showed Pneumocystis jiroveci, Staphylococcus aureus/MSSA, Candida dubliniensis, Cytomegalovirus and Legionella pneumophila. Blood tests showed signs of a disseminated Cytomegalovirus infection with 13.800 copies per ml CMV DNA. Renal replacement therapy was started. On day 5 after admission to the ICU, the patient's condition was rapidly deteriorating $\left(\mathrm{FiO}_{2} / \mathrm{paO}_{2}\right.$ 50-60, pressure control ventilation, PEEP 14 mbar, Pmax 31, $\mathrm{paCO}_{2}$ 66, $\mathrm{pH} 7.12, \mathrm{BE}$ - 7.8). Due to continuing severe septic shock (Lactat 8.3 $\mathrm{mmol} / \mathrm{l}$, Norepinephrine $1.5 \mu \mathrm{g} / \mathrm{kg} / \mathrm{min}$ ) and persistent risk of hypoxemia after interdisciplinary discussion extracorporal veno-venous oxygenation was established. In cases of septic shock extracorporal veno-arterial oxygenation is often limited due to higher heart time volumes in sepsis and developing harlequin phenomenon with insufficient systemic oxygenation. In these cases a veno-veno-arterial ECMO might be an option if the cardiac function is sufficient. After the start of veno-venous ECMO therapy, the patient stabilized slowly and the lactate levels decreased. There was no need for an additional arterial cannulation.
Anti-infective therapy was expanded to cover the detected and suspected pathogen spectrum: Legionella pneumophila (Azithromycin, Levofloxacin), Staphylococcus aureus/MSSA (Linezolid), Pneumocystis jirovecii (Trimethoprim/Sulfamethoxazole), Candida dubliniensis (Anidulafungin), Cytomegalovirus (Ganciclovir). In addition an antibody deficiency syndrome was treated with intravenous IgM-enriched immunoglobulin (Pentaglobin ${ }^{\circ}$ ) substitution. FACS analysis showed a decreased subset of T-suppressor cells $(\mathrm{CD} 3+\mathrm{CD} 8+/ \mathrm{CD} 45+)$ and NK Lymphocytes (CD16+56+/CD45+) (Fig. 2). On day 6 , signs of hepatic failure and disseminated intravascular coagulation were developing with rapidly declining platelet count and coagulation parameters, in spite of repeated transfusion and substitution. Lactate levels were rising and CT scan now showed massive bipulmonary infiltration with multiple pulmonary embolism and signs of kidney and cerebral ischemia due to disseminated embolism. This was primarily interpreted as a sign of disseminated intravascular coagulation but echocardiography was scheduled for the following day to rule out endocarditis and anticoagulation was switched from

Panel Name: Immunstatus

\section{CD3/CD8/CD45/CD4}

Reagent Lot ID: 00000 Events Acquired: 94600

File ID: 9414DC08-

F0CC-11E5-8A78-00306549

D26C

\begin{tabular}{|lc|}
\hline Lymph Events & 2497 \\
CD3+ \%Lymph & 55.15 \\
CD3+CD8+\%Lymph & 11.93 Lo \\
CD3+CD4+ \%Lymph & 44.25 \\
CD3+CD4+CD8+ \%Lymph & 1.64 \\
T H/S Ratio & 3.71 \\
\hline
\end{tabular}

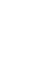

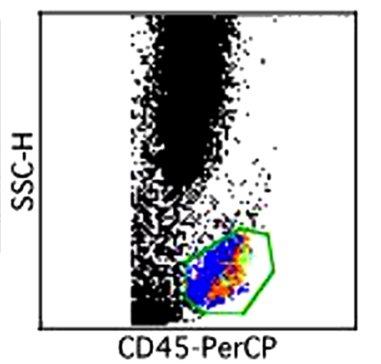
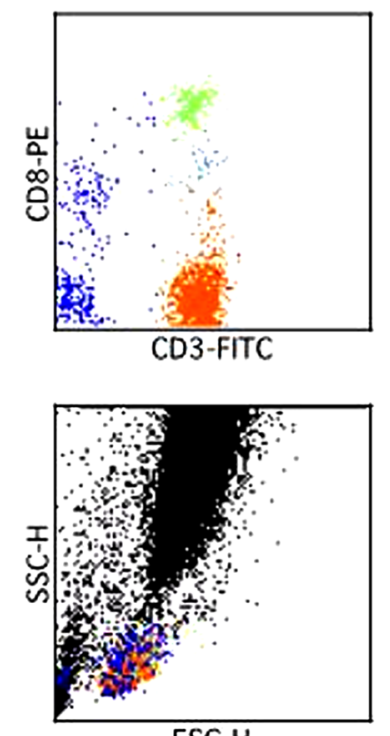

FSC-H
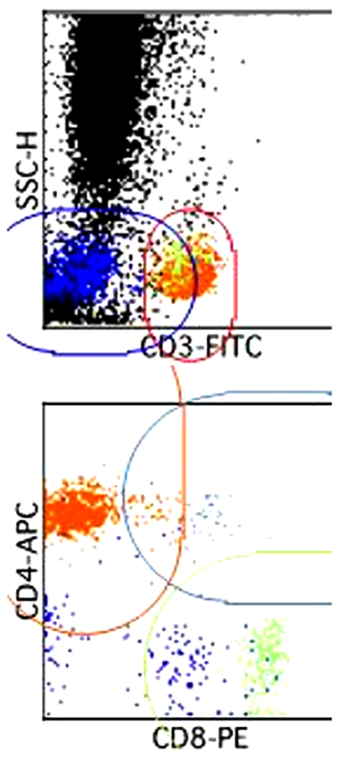

QC Messages:

Code $4:$ The $C D 3+C D 8+\%$ Lymph value lies outside the normal reference range.

Fig. 2 T-cell distribution on day 3 after admission 
Heparin to Argatroban. Blood samples were sent to an extern laboratory to rule out HIT. Based on the impaired hemeostasis with severe thrombopenia $(14.000 / \mu \mathrm{l})$, biopsie on ECMO was abandoned and echocardiography postponed.

On day 7 after the initiation of anti-infective therapy Candida glabrata, Pneumocystis jiroveci, Cytomegalovirus and Legionella pneumophila were still present in BAL cultures. Even though MSSA was not detected anymore, Flucloxacillin was added to cover all bases and Anidulafungin was changed to Voriconazol.

Still, there were no signs of improvement. The signs of pulmonary, renal and hepatic failure and clinical signs of disseminated intravascular coagulation were still progressing. D-Dimers rose up to $42 \mu \mathrm{g} / \mathrm{ml} \mathrm{FEU.} \mathrm{When} \mathrm{the}$ patient failed to awake after discontinuation of sedation we again performed CT scan on day 12. The massive bipulmonary infiltration was again progressing with signs of possible pulmonary hemorrhage (Fig. 3). The CT scan of the brain showed diffuse intracerebral hemorrhages with signs of increased intracranial pressure. Without further options and no achievable therapeutic goal extracorporeal membrane oxygenation was stopped. The patient died within minutes.

The autopsy revealed the following findings:

1. Extensive intracerebral hemorrhage of both hemispheres, with emphasis of the left side, with cerebral edema and signs of hypoxic encephalopathy, as well as upper and lower herniation. No signs of fungal infiltration inside the brain.
2. Intramedullary malignant melanoma at the height of thoracic vertebra 1.

3. Massive infarct pneumonia on both sides. Lung parenchyma with evidence of Mucor and Aspergillus mycelium with angio-invasive/-destructive and focal bronchi-destructive growth. Focal parenchymatous hemorrhage on both sides. (Fig. 4)

4. Numerous infarctions (max. $0.5 \mathrm{~cm}$ ) with focal Aspergillus and Mucor colonization in the myocardium. Accompanied by a very pronounced phlegmonous purulent myocarditis. (Fig. 5, right)

5. Kidneys: On both sides numerous infarctions (max. $1.5 \mathrm{~cm}$ ) with Aspergillus and Mucor colonization with angio-invasive and glomeruli-destructing growth. Acute renal failure.

6. Multiple sharply delineated ulcer with raised margins and focal Aspergillus and Mucor colonization, predominantly in the corpus and antrum of the stomach, as well as in the whole colon.

7. Chronic recurrent pancreatitis with fatty necrosis. Several stray herds with Mucor and Aspergillus mycelium detection. (Fig. 5, left)

8. No fungus detection in paraaortal lymph nodes but aspergillus and Mucor colonization in the adjoining tissue.

\section{Discussion and conclusions}

ARDS may be caused by a variety of conditions and mortality remains high. Even more so if the patient is immunocompromised due to medical therapy or infection. Fungal infections are hardly ever the first pathogens

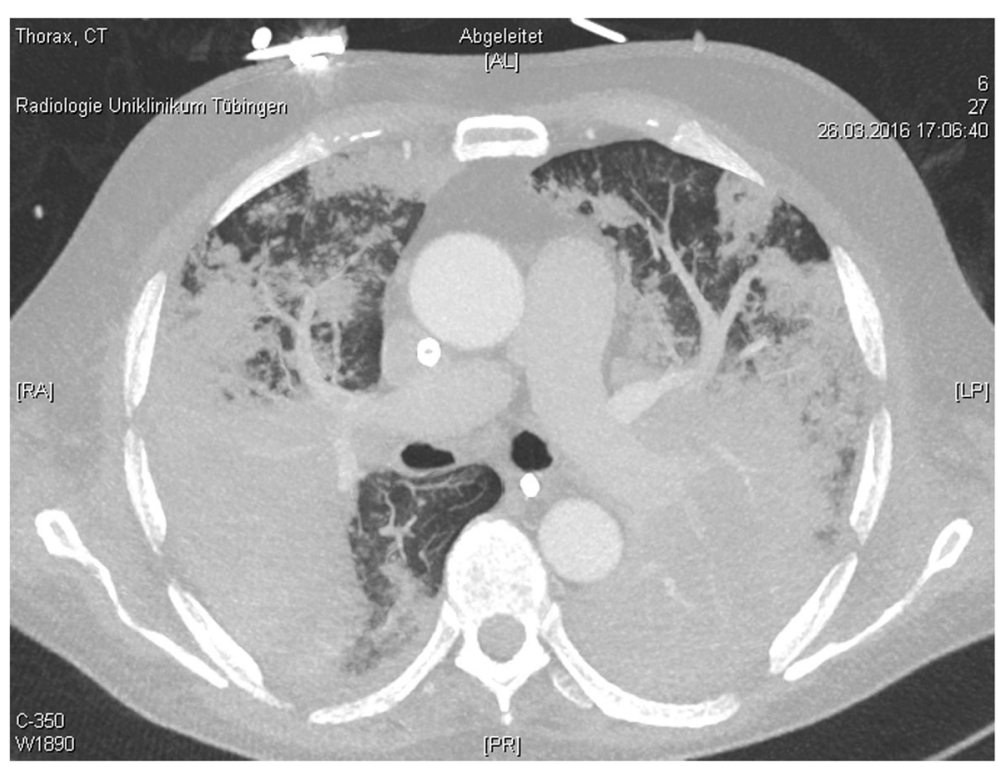

Fig. $3 \mathrm{CT}$ scan of the lung on day 12 after admission 

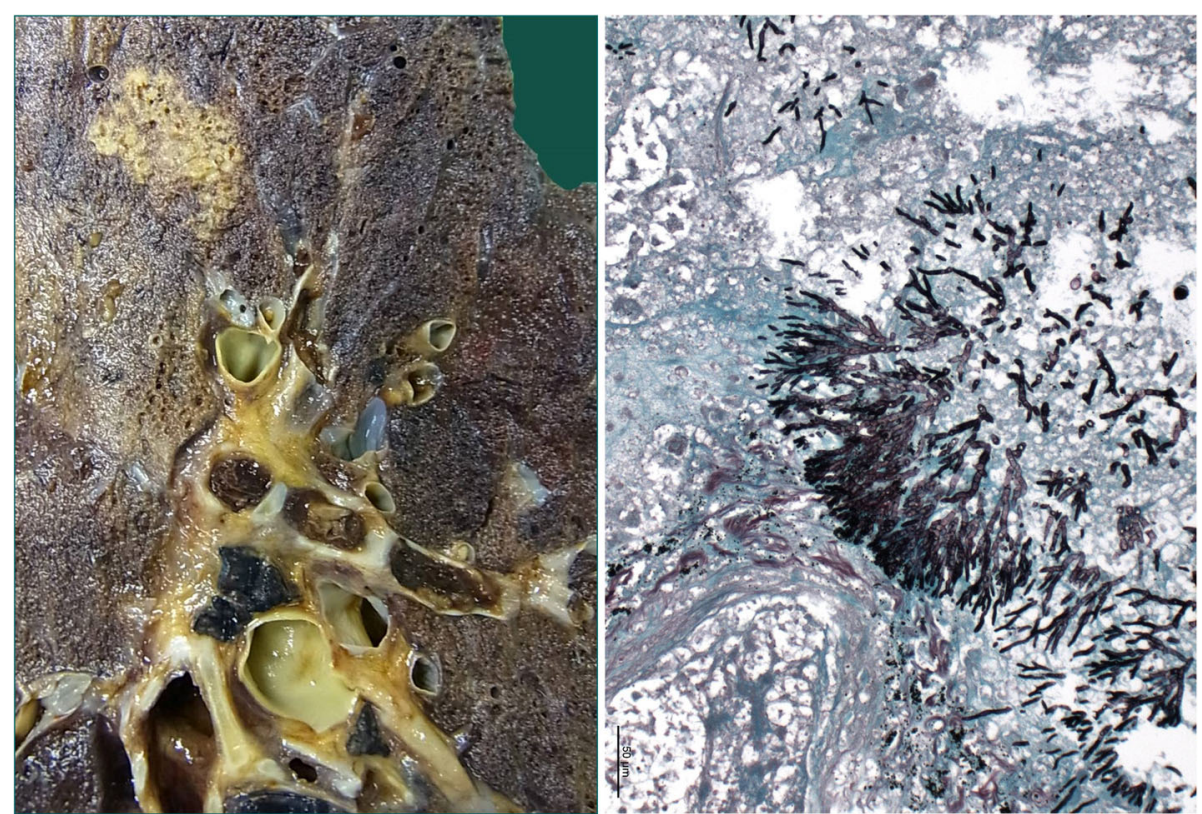

Fig. 4 lung tissue, macroscopy (left) and Grocott-Gomori methenamine silver stain (right)

thought of, but fungal coinfections were described in children suffering ARDS due to viral infection [2]. Risk factors for fungal infections in ICU-patients are numerous, including immunosuppressive drugs and the differentiation of contamination or infection in nonhematological patients is challenging.

In this case the decision to deescalate and stop the therapy was based on the CT scan of the brain. The scan showed diffuse intracerebral hemorrhages with signs of increased intracranial pressure. The situation was evaluated and deemed to be infaust. With the knowledge of the autopsy findings, the overall situation of the mucor infection must now also be regarded as hopeless. Our initial discussion and decision to establish ECMO therapy was based upon the facts known at the time.

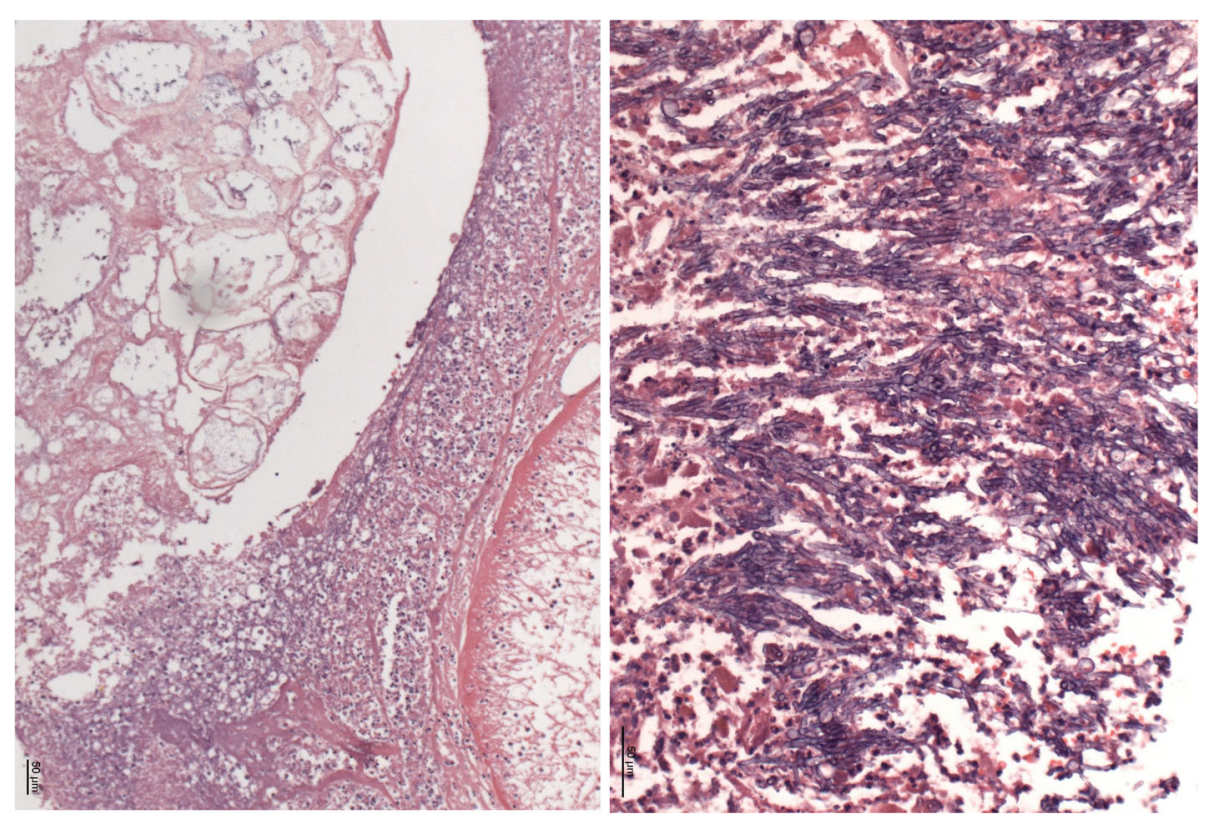

Fig. 5 Pancreas tissue (left) and Myocard tissue (right) 
Although the reported single cases about mucormycosis increased lately, they are rare. Most cases were described in patients with malignancies, organ transplantation, HIV or DM (recently reviewed in [12]). Our patient was affected by none of these diseases but had received corticoid therapy and was therefore immunocrompromised.

There is some evidence, that mucormycosis and aspergillosis may be linked to previous antifungal therapy [14] although mainly in patients with hematological disorders. Therefore the onset of antifungal therapy is an important issue. Based on the expert opinion of the European Society of Anesthesia Intensive Care Scientific Subcommittee [15] the decision pathway in this case was correct. Initially the colonization index was $<0.5$; candida score $<3$. PCR- and Serum-tests were negative for fungal infection. 1,3-Beta-D-Glucan was not applied. However, the interpretation of this marker in patients infected by pneumocystis may be challenging [16]. The serological test (Platelia; Bio Rad; München) did not prove positive Aspergillus-Galaktomannan-Antigen until 2 days before the patient's death. In addition diagnosis of pulmonary mucormycosis by conventional culture may be difficult due to overgrowth. Microscopical examination of BAL may lead to misinterpretation due to contamination. Histopathological examination may be a valid option, although it is of risk in patients with anticoagulation and/or disseminated intravascular coagulation $[8,17]$. Recently Jiang and coworkers suggested the liquid-based cytopathology to identify mucorales promptly in samples obtained by bronchial brushes, which could be a less invasive method to detect this infection promptly [13].

Considering and even re-considering frequent risk factors of fungal infections, e.g. mucormycosis and aspergillus, might be more fruitful than pursuing the question of how to provide evidence of the pathogen. There is no evidence but according to data obtained in the few hundred known cases of mucormycosis, history of poorly controlled diabetes in combination with impaired cellmediated immune function including neutropenia are mainly the issue. Recent data suggests that $T$ cells may play an important role in host defense to fungal disease $[18,19]$. Like in our patient, lymphopenia may be an important indicator for the application of frequent fungal screening and fungal prophylaxis.

Routine screening before starting an antifungal prophylaxis and frequent re-evaluation of every infection are essential for adequate initiation and discontinuation of every fungal therapy especially with patients at high risk for fungal infections. All patients receiving immunosuppressive therapy, for whatever reason, must be included in this group. In case of assumed mucor infection the decision for biopsy should be taken into account for
ARDS patients with progressive lung inflammation of unknown origin when all standard samples fail to provide an edaquate explanation for the patients status, since the risk to die due to mucor may outweigh the risk of fatal bleeding due to the biopsy. But this decision needs to be based on a detailed risk/benefit analysis for each patient.

\section{Abbreviations \\ ARDS: Acute respiratory distress syndrome; BAL: Bronchoalveolar lavage; CMV: Cytomegalovirus; DNA: Desoryribonucleic acid; CRP: C-reactive protein; $C T$ : Computed tomography; DIC: Disseminated intravascular coagulation; DM: Diabetes mellitus; ECMO: Extracorporeal membrane oxygenation; FACS: Fluorescence activated cell sorting; $\mathrm{FiO}_{2}$ : Fraction of inspired oxygen; $\mathrm{paO}_{2}$ : Arterial partial pressure of oxygen; HIT: Heparin induced thrombocytopenia; HIV: Human immunodeficiency virus; ICU: Intensive care unit; IgM: Immunoglobulin M; INR: International normalized ratio; MSSA: Methicillin sensitive Staphylococcus aureus; PCR: Polymerase chain reaction; PCT: Procalcitonin; Pmax: Peak pressure}

\section{Acknowledgements}

The authors would like to thank all their colleges for their support and help. In addition we would like to thank the Department of Radiology for the access to the CT scan and their help to create those special figures.

\section{Authors' contributions}

PS: Preparation of the manuscript, preparation of Figs. HP: Collection of data, review of manuscript. WS: Preparation of figures, review of manuscript. FL: Preparation of figures, review of manuscript. RP: review of manuscript. HHA review of manuscript. All authors read and approved the final manuscript.

\section{Funding}

We acknowledge support by Deutsche Forschungsgemeinschaft and Open Access Publishing Fund of University of Tübingen to cover article-processing charges.

\section{Availability of data and materials}

Additional clinical data is available on request. Please contact the corresponding author for any additional clinical data. This case report contains five figures.

All figures have been uploaded with the manuscript.

Ethics approval and consent to participate

Not applicable.

\section{Consent for publication}

Since the Patient died, written consent to publish was obtained from his wife and legal representative. Consent was given on August 23rd 2019.

\section{Competing interests}

The authors are not aware of any competing interests concerning this publication.

\section{Author details}

${ }^{1}$ Department of Anesthesiology and Intensive Care Medicine, Intensivstation 39, Tübingen University Hospital, Eberhard-Karls-University, Hoppe-Seyler-Str. 3, 72076 Tübingen, Germany. ${ }^{2}$ Department of Pathology, Tübingen University Hospital, Eberhard-Karls-University, Tübingen, Germany.

Received: 10 September 2019 Accepted: 3 May 2020

Published online: 07 May 2020

\section{References}

1. Cortegiani A, Madotto F, Gregoretti C, Bellani G, Laffey JG, Pham T, Van Haren F, Giarratano A, Antonelli M, Pesenti A, Grasselli G. Investigators LS, the ETG. Immunocompromised patients with acute respiratory distress syndrome: secondary analysis of the LUNG SAFE database. Crit Care. 2018; 22:157. 
2. Phung TTB, Suzuki T, Phan PH, Kawachi S, Furuya H, Do HT, Kageyama T, Ta TA, Dao NH, Nunoi H, Tran DM, Le HT, Nakajima N. Pathogen screening and prognostic factors in children with severe ARDS of pulmonary origin. Pediatr Pulmonol. 2017:52:1469-77.

3. Alobaid K, Alfoudri H, Jeragh A. Influenza-associated pulmonary aspergillosis in a patient on ECMO. Med Mycol Case Rep. 2020:27:36-8.

4. Vanderbeke L, Spriet I, Breynaert C, Rijnders BJA, Verweij PE, Wauters J. Invasive pulmonary aspergillosis complicating severe influenza: epidemiology, diagnosis and treatment. Curr Opin Infect Dis. 2018;31: $471-80$.

5. Avino $L$, Naylor SM, Roecker AM. Pneumocystis jirovecii Pneumonia in the Non-HIV-Infected Population. Ann Pharmacother; 2016.

6. Kotton CN, Kumar D, Caliendo AM, Huprikar S, Chou S, Danziger-Isakov L, Humar A, Group TTSICC. The Third International Consensus Guidelines on the Management of Cytomegalovirus in Solid-organ Transplantation. Transplantation. 2018;102(6):900-31.

7. Bongomin F, Gago S, Oladele RO, Denning DW. Global and multi-National Prevalence of fungal diseases_estimate precision. J Fungi (Basel). 2017;3(4): 57.

8. Cornely OA, Cuenca-Estrella M, Meis JF, Ullmann AJ. European Society of Clinical Microbiology and Infectious Diseases (ESCMID) fungal infection study group (EFISG) and European Confederation of Medical Mycology (ECMM) 2013 joint guidelines on diagnosis and management of rare and emerging fungal diseases. Clin Microbiol Infect. 2014;20(Suppl 3):1-4.

9. Cornely OA, Bassetti M, Calandra T, Garbino J, Kullberg BJ, Lortholary O, Meersseman W, Akova M, Arendrup MC, Arikan-Akdagli S, Bille J, Castagnola E, Cuenca-Estrella M, Donnelly JP, Groll AH, Herbrecht R, Hope WW, Jensen HE, Lass-Floerl C, Petrikkos G, Richardson MD, Roilides E, Verweij PE, Viscoli C, Ullmann AJ, Group EFIS. ESCMID guideline for the diagnosis and management of Candida diseases 2012: non-neutropenic adult patients. Clin Microbiol Infect. 2012;18:19-37.

10. Pappas PG, Kauffmann CA, Andes DR, Clancy CJ, Marr KA, Ostrosky-Zeichner L, Reboli AC, Schuster MG, Vazques JA, Walsh TJ, Zaoutis TE, Sobel JD. Clinical Practice Guideline for the Management of Candidiasis: 2016 Update by the Infectious Diseases Society of America. Clin Infect Dis. 2016;62:e1-50.

11. Ullmann AJ, Aquado JM, Arikan-Akdagli S, Denning DW, Groll AH, Lagrou K, Lass-Floerl C, Lewis RE, Munoz P, Verweij P, Warris A, Ader F, Akova M, Arendrup MC, Barnes RA, Beigelman-Aubry C, Blot S, Bouza E, Brüggemann RJM, Buchheidt D, Cadranel J, Castagnola E, Chakrabarti A, Cuenca-Estrella M, Dimopoulos G, Fortun J, Gangneux JP, Garbino J, Heinz WJ, Herbrecht R, Heussel CP, Kibbler CC, Klimko N, Kullberg BJ, Lange C, Lehrnbecher T, Löffler J, Lortholary O, Maertens J, Marchetti O, Meis JF, Pagano L, Ribaud P, Richardson M, Roilides E, Ruhnke M, Sanguinetti M, Sheppard DC, Sinko J, Skiada A, Vehreschild MJGT, Viscoli C, Cornely OA. Diagnosis and management of Aspergillus diseases: executive summary of the 2017 ESCMID-ECMM-ERS guideline. Clin Microbiol Infect. 2018;24:e1-e38.

12. Yamin HS, Alastal AY, Bakri I. Pulmonary Mucormycosis over 130 years: a case report and literature review. Turk Thorac J. 2017;18:1-5.

13. Jiang X, Yang T, Li Q, Zhu X, Su X, Li J, Jiang Y. Liquid-based cytopathology test: a novel method for diagnosing pulmonary Mucormycosis in bronchial brushing samples. Front Microbiol. 2018;9:2923.

14. Guinea J, Escribano P, Vena A, Munoz P, Martinez-Jimenez MDC, Padilla B, Bouza E. Increasing incidence of mucormycosis in a large Spanish hospital from 2007 to 2015: epidemiology and microbiological characterization of the isolates. PLoS One. 2017;12:e0179136.

15. O'Leary RA, Einav S, Leone M, Madach K, Martin C, Martin-Loeches I. Management of invasive candidiasis and candidaemia in critically ill adults: expert opinion of the European Society of Anaesthesia Intensive Care Scientific Subcommittee. J Hosp Infect. 2018;98:382-90.

16. Lahmer T, da Costa CP, Held J, Rasch S, Ehmer U, Schmid RM, Huber W. Usefulness of 1,3 Beta-D-Glucan detection in non-HIV Immunocompromised mechanical ventilated critically ill patients with ARDS and suspected Pneumocystis jirovecii pneumonia. Mycopathologia. 2017;182:701-8.

17. Combes A, Hajage D, Capellier G, Demoule A, Lavoue S, Guervilly C, Da Silva D, Zafrani L, Tirot P, Veber B, Maury E, Levy B, Cohen Y, Richard C, Kalfon P, Bouadma L, Mehdaoui H, Beduneau G, Lebreton G, Brochard L, Ferguson ND, Fan E, Slutsky AS, Brodie D, Mercat A, Eolia Trial Group R, Ecmonet. Extracorporeal membrane oxygenation for severe acute respiratory distress syndrome. N Engl J Med. 2018;378:1965-75.

18. Arens C, Kramm T, Decker S, Spannenberger J, Brenner T, Richter DC, Weigand MA, Uhle F, Lichtenstern C. Association of Immune Cell Subtypes and Phenotype with Subsequent Invasive Candidiasis in Patients with Abdominal Sepsis. Shock. 2019;52(2):191-97.

19. Zhang J, Cui N, Long Y, Wang H, Han W, Li Y, Xiao M. Prospective evaluation of lymphocyte subtyping for the diagnosis of invasive candidiasis in non-neutropenic critically ill patients. Int J Infect Dis. 2019;78:140-7.

\section{Publisher's Note}

Springer Nature remains neutral with regard to jurisdictional claims in published maps and institutional affiliations.
Ready to submit your research? Choose BMC and benefit from:

- fast, convenient online submission

- thorough peer review by experienced researchers in your field

- rapid publication on acceptance

- support for research data, including large and complex data types

- gold Open Access which fosters wider collaboration and increased citations

- maximum visibility for your research: over $100 \mathrm{M}$ website views per year

At BMC, research is always in progress.

Learn more biomedcentral.com/submissions 